\title{
Percutaneous Transforaminal Endoscopic Lumbar Discectomy in Obese Patients
}

\author{
IHAB A.M. HOSNY, M.D. and MOHAMED K. ISMAIL, M.D. \\ The Department of Orthopedic Surgery, Armed Forces Collage of Medicine
}

\begin{abstract}
Background: Obese patients are at higher risk of complications after spinal surgery such as slower wound healing and increased infection rates. Percutaneous Endoscopic Lumbar Discectomy (PELD) has advantages over conventional microdiscectomy because it decreases perioperative complications and increases favorable clinical outcomes.
\end{abstract}

Aim of Study: The aim of this study is to evaluate the clinical outcomes of PELD in obese patients as compared to patients who have a normal body mass index.

Patients and Methods: Obesity is defined as a Body Mass Index (BMI) of more than $30 \mathrm{~kg} / \mathrm{m}^{2}$. Our study included 32 obese patients and 35 normal BMI patients treated by PELD for radiating pain caused by a single-level lumbar disc herniation. Clinical and functional outcomes using Visual Analogue Scale (VAS) and Oswestry Disability Index (ODI) and followup was done at 2 weeks, 1, 2, 6 and 12 months post-operatively. All surgeries were done by the same surgeon.

Results: Overall clinical and functional outcomes were improved during post-operative follow-up evaluation. There were no immediate perioperative complications, such as infection or durotomy in both groups. In the obese group, two patients had late re-herniation, of these, 1 patients had tolerable pain and showed good recovery with conservative treatment; 1 patient underwent another PELD surgery. In control group, there was one early reherniations which occurred within a months after PELD, which patient underwent conventional microdiscectomy.

Conclusion: PELD is an effective, safe, and minimally invasive technique for obese patients. The PELD decreases the post-operative morbidity and allows for faster mobility and rehabilitation. The results were comparable to patients with normal body mass index.

Key Words: Transformational - Endoscopic - Discectomy Obesity.

\section{Introduction}

OBESITY represents one of the most serious global health issues. Over 3000 million adults

Correspondence to: Dr. Ihab A.M. Hosny, The Department of Orthopedic Surgery, Armed Forces Collage of Medicine worldwide are obese. It has been reported that the prevalence of obesity in adults is very high in Egypt, particularly among women [1]. Obesity increases the incidence of disc herniation in adult not only due to increased mechanical load but also accelerating its degeneration [2] .

When spine surgeries are planned for obese patients, several factors must be considered. Obesity is closely correlated with additional medical comorbidities including hypertension, coronary artery disease, and diabetes mellitus. After surgery, obese patients are at higher risk for wound infection and deep vein thrombosis. Nevertheless, appropriate clinical outcomes can be achieved in obese patients who undergo spine surgery [3]

Current surgical treatments in obese patients use a large incision to allow adequate visualization at depth; however, this causes paraspinal tissue injury, which is associated with perioperative morbidity. For morbidly obese patients who underwent open spinal surgery, a complication rate as high as $50 \%$ has been reported [4]

Percutaneous Transforaminal Endoscopic Lumbar Discectomy (PELD) has been developed as a minimally invasive spinal surgery for soft disc herniation. PELD provides some benefits over open discectomy, such as less damage to paraspinal soft tissue, shorter hospital stays, and earlier return to work [5].

This study was performed to evaluate outcomes and the incidence of perioperative complications after PELD in obese patients.

\section{Patients and Methods}

Obesity is defined in terms of BMI, which is calculated as body weight in kilograms divided by height in square meters. Patients with a BMI of 
$30 \mathrm{~kg} / \mathrm{m}^{2}$ or higher were considered to be obese and patients with a BMI of $18.5-22.9 \mathrm{~kg} / \mathrm{m}^{2}$ were considered to be normal [6]

A prospective study including a total of 83 patients who underwent PELD between January 2019 and December 2019. The obese group included 32 patients with BMI of more than $30 \mathrm{~kg} / \mathrm{m}^{2}$ who completed the follow-up period. The control group included 35 patients with normal BMI between $18.5 \mathrm{~kg} / \mathrm{m}^{2}$ and $22.9 \mathrm{~kg} / \mathrm{m}^{2}$ who completed the follow-up period. Other patients with overweight or lack of follow-up were excluded.

\section{Inclusion criteria:}

The study participants were patients with unilateral leg pain associated with soft disc herniation as determined by plain X-ray, Magnetic Resonance Imaging (MRI) and Computed Tomography (CT). Additionally, patients suffering from persistent pain after 6 weeks of conservative treatment, involving rest, analgesia, and physical therapy were included. Physical examination showed a positive nerve root tension sign.

\section{Exclusion criteria:}

1- Patients of lumbar canal stenosis (central or lateral).

\section{2- Bilateral sciatica.}

3- Sciatica due to other pathologic conditions (fracture, trauma, tumor, infection).

4- Cases of sciatica with complete disc collapse.

5- Cases of spinal instability.

6- Highly migrated disc.

7- Foraminal spur or bony compression.

8- Cases which did not complete the follow-up.

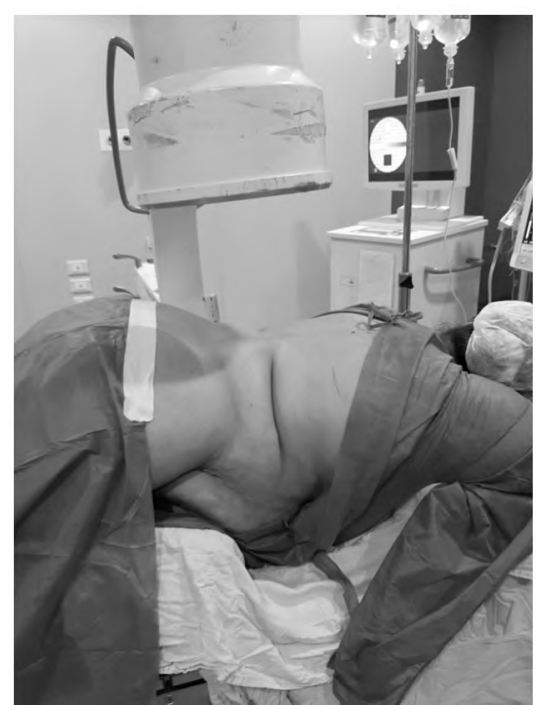

Clinical outcomes were assessed using the visual analogue scale (VAS; $0-10$, with $0=$ No pain), and functional outcomes were scored according to the Oswestry Disability Index (ODI; 0$100 \%$ ), and return to work status. Follow-up was done at 2 weeks 1, 2, 6 and 12 months postoperatively. All surgeries were done by the same surgeon.

Additionally, presence of comorbidities, operating time, length of hospital stay, and perioperative complications were evaluated. During the postoperative follow-up period, MRI was performed when the patient complained of newly developed radiating pain. For all other patients without new symptoms, only a clinical follow-up was conducted.

After ethical committee approval, all patients signed an informed and detailed consent before any procedure; the surgeries were performed in Al-Helmya Military Hospital.

Statistical methods: All data were entered into the SPSS statistical program (version 14.0K; SPSS Inc., Chicago, IL). Statistical tests included analysis of variance using the matched 2-sample $t$-test and Wilcoxon signed ranks test. Results were considered statistically significant if $p$ was $<0.05$.

\section{Operative technique:}

All patients received $2 \mathrm{~g}$ third generation cephalosporin intravenously as antibiotic prophylaxis, patients placed on a radiolucent table in the prone position. His/her knee is flexed and draped aseptically, Anteroposterior (AP) and lateral view before needling this will avoid radiographic error and malposition of the needle, cannula and the endoscope. All procedures were done under local anesthesia with monitoring and additional sedation can be used when needed.

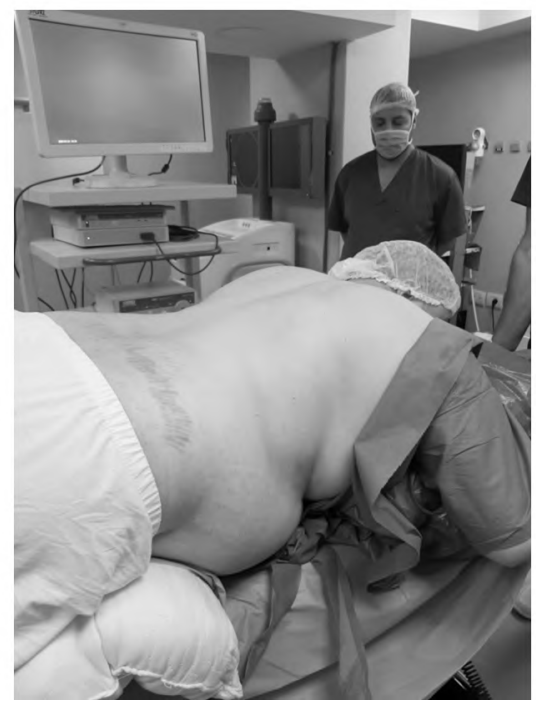

Fig. (1): Showing two obese patient a female an a male on the operating table. 

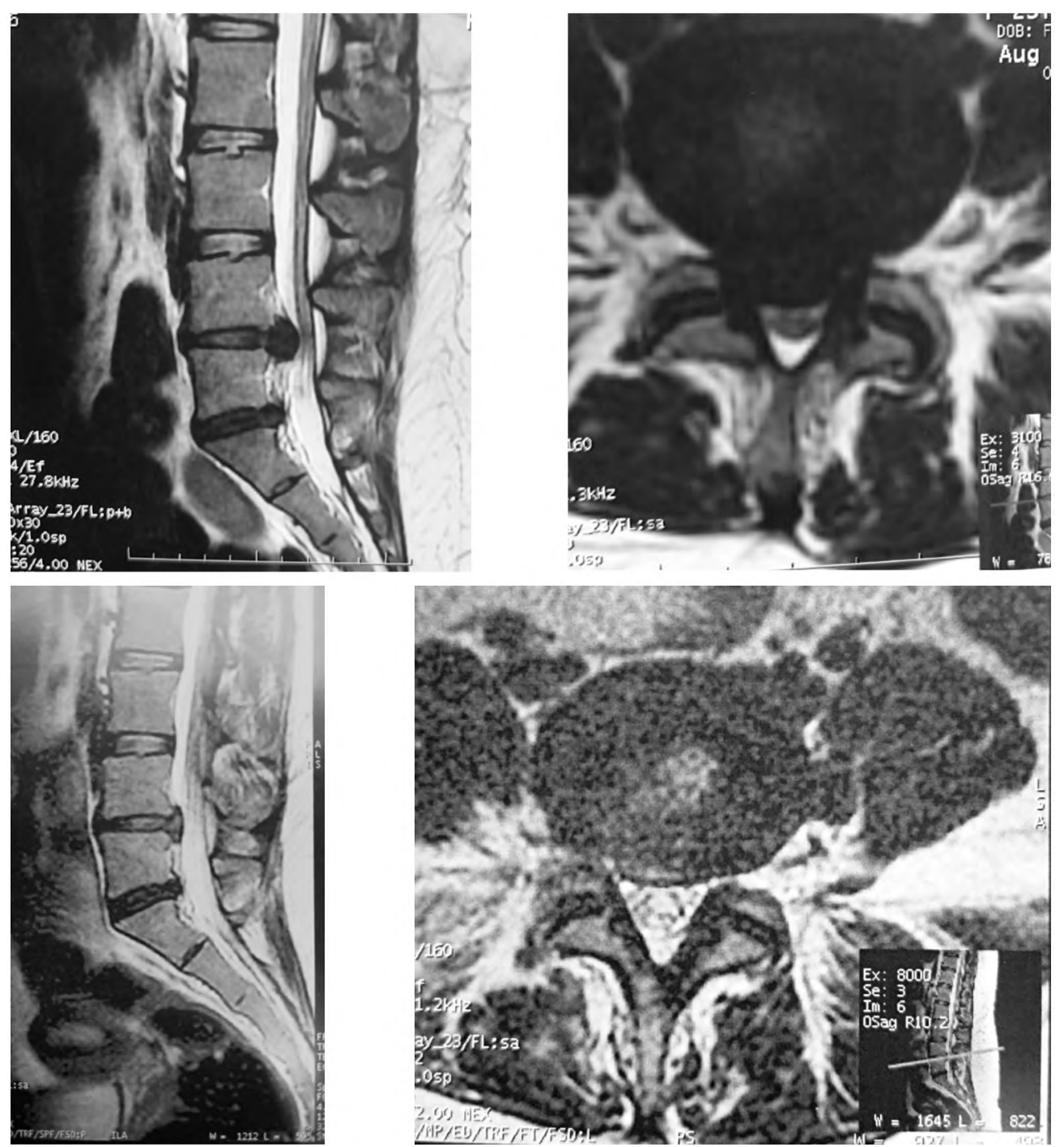

Fig. (2): A female patient aged 25 years had an L4-5 disc herniation with post-operative MRI showing adequate decompression.
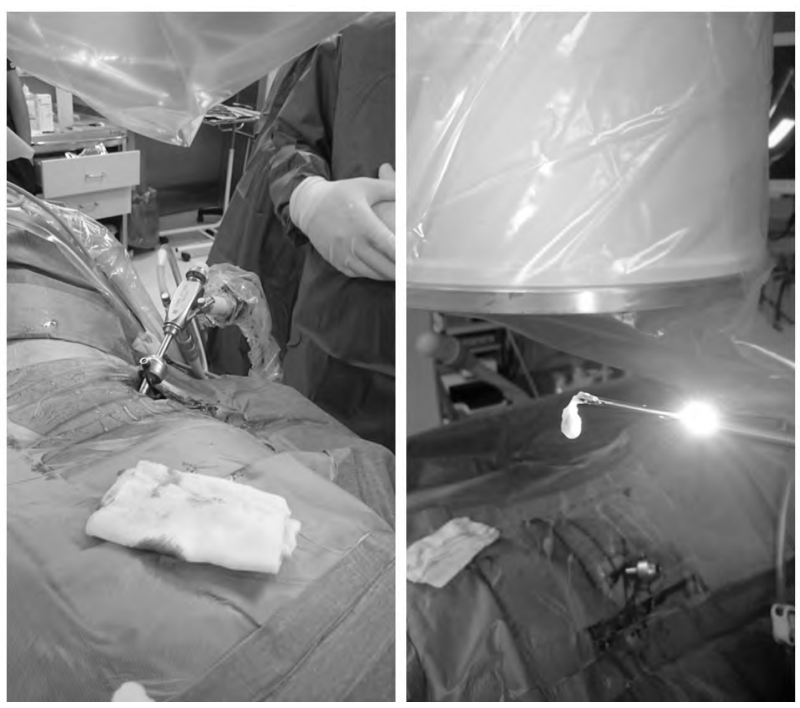

Fig. (3): Showing line drawing and scope and a fragment removed.
Needling: All lumbar area painted with iodine and draping was done wide enough. Skin, fascia, muscles were infiltrated with $1 \%$ lidocaine. Proper endoscopic view targeting the fragment depends on the initial placement of the needle. The needle entry point typically starts about 10 to $14 \mathrm{~cm}$ from the midline, to optimize the approach to access the specific herniation type, the entry point can be a little more medial (for foraminal or extraforaminal discs) or lateral (for central and some paracentral disc). Typically, start as lateral as possible to create a shallow entry trajectory (15-20 degree to the floor) to the lateral facet, then slide the needle ventral to the facet, using the facet as a lever arm. An 18 gauge aspiration needle ( 21 inch length) inserted from the entry point to land in the foramen at the medial pedicular line in $\mathrm{A} / \mathrm{P}$ view and at the posterior vertebral line in the lateral view, then the needle was advanced into the disc to be in the 
midline in $\mathrm{A} / \mathrm{P}$ view and in the posterior quadrant in the lateral view. The stylet of the needle was removed, a guide wire was passed into the disc space and the needle removed. Skin was incised at the entry point for an $8 \mathrm{~mm}$ length; local anesthetic was given by using the side channel. Check again the dilator was inside the disc, remove the guide wire, put the operation sheath over the dilator, then the dilator was removed and the endoscope was inserted through the operation sheath. Most of the cases operated by in-out technique but sometimes we used out-in technique and half-half technique, the disc was seen directly and the fragment was removed. Bleeding control was done by continuous washing during procedure and by bipolar cautery. Before removing the endoscope, we also routinely visualize and confirm the pulsations of the traversing and exiting nerve root. Once discectomy was finished, the endoscope and operative sheath were removed.

Post-operatively: All patients were allowed to ambulate on the same post-operative day as soon as they can independently walk and discharged within 24 hours. Post-operative oral antibiotics and analgesics are given for 3-7 days following surgery.

\section{Results}

The obese group comprised 13 (40.6\%) men and $19(59.4 \%)$ women, with a mean age of 40.7 years (range, 20-65 years). Their mean BMI was $33.5 \mathrm{~kg} / \mathrm{m}^{2}$ (range, $30.1-39.5 \mathrm{~kg} / \mathrm{m}^{2}$ ).

Ten $(31.3 \%)$ of the thirty two patients had comorbidities such as hypertension, heart disease, diabetes, and fatty liver. The control group comprised $20(57.2 \%)$ men and $15(42.8 \%)$ women, with a mean age of 35.5 years (range, 19-62 years). Their mean BMI was $21.3 \mathrm{~kg} / \mathrm{m}^{2}$ (range, 18.4-22.9 $\mathrm{kg} / \mathrm{m}^{2}$ ). Two $(6.7 \%)$ of the 35 patients had comorbidities such as hypertension and fatty liver.
The affected spinal levels were mostly L4-5 and L5-S 1 level in both groups.

Table (1): Summary of patients' demographics and clinical characteristics.

\begin{tabular}{lll}
\hline & Obesity & Control \\
\hline Number of patient & 32 & 35 \\
Gender (males/females) & $13 / 19$ & $20 / 15$ \\
Average age (years) (range) & 40.7 & 38.1 \\
BMI $\left(\mathrm{kg} / \mathrm{m}^{2}\right.$ ) (range) & 33.5 & 21.3 \\
Discectomy level (cases): & & \\
L3-4 & 2 & 0 \\
L4-5 & 18 & 17 \\
L5-S1 & 10 & 13 \\
Recurrent herniation & 2 & 1 \\
\hline
\end{tabular}

Obese and control patients spent respectively a mean of $45 \mathrm{~min}$ (range, $30-105 \mathrm{~min}$ ) and $40.8 \mathrm{~min}$ (range, $35-75 \mathrm{~min}$ ) in surgery. The amount of disc material removed were nearly the same $0.8 \mathrm{cc}$ (range, $0.5-2.1 \mathrm{cc}$ ). The mean length of hospital stays of obese and control patients were 1 day (range, 1-3 days) and 1 day (range, 1-2 days), respectively.

Table (2) shows that there is a statistically significant difference between pre-operative and post-operative assessments in both groups which indicates that cases show a significant improvement post-operative.

Table (3) shows that there is no statistically significant difference between the post-operative assessments of both groups which indicates that the result of PELD in obese patients is comparable to PELD in non obese patients.

Table (2): Pre-and post-operative clinical and functional outcome in obesity and control group.

\begin{tabular}{lllllllll}
\hline & \multicolumn{3}{c}{ Obese } & & \multicolumn{3}{c}{ Control } \\
\cline { 2 - 4 } \cline { 7 - 9 } & Pre-op. & Post-op. & $p$ & & Pre-op. & Post-op. & $p$ \\
\hline VAS (back) & $5.4(1.9)$ & $1.8(2.5)$ & 0.001 & & $4.8(1.9)$ & $2.2(1.3)$ & 0.01 \\
VAS (leg) & $8.1(1.7)$ & $1.8(1.8)$ & $<0.0001$ & $7.8(1.4)$ & $1.4(1.5)$ & $<0.0001$ \\
ODI (\%) & $62.3(16.1)$ & $8.8(12.3)$ & $<0.0001$ & $61.5(19.6)$ & $12(5.3)$ & $<0.0001$ \\
Return to work status & & $100 \%$ & $\mathrm{ND}$ & & $100 \%$ & $\mathrm{ND}$ \\
\hline
\end{tabular}

VAS: Visual Analogue Scale.

ODI: Oswestry Disability Index.

ND : Not Determined.

Mean value (standard deviation). $p$-values determined by matched two-sample $t$-test. 
Table (3): Comparison of pre-and post-operative clinical and functional outcomes between obesity and control group.

\begin{tabular}{llllllc}
\hline & \multicolumn{3}{c}{ Pre-operative } & \multicolumn{3}{c}{ Post-operative } \\
\cline { 2 - 7 } & \multicolumn{1}{c}{ Obese } & Control & $p$ & Obese & Control & $p$ \\
\hline VAS (back) & $5.4(1.9)$ & $4.8(1.9)$ & 0.181 & $1.8(2.5)$ & $2.2(1.3)$ & 0.520 \\
VAS (leg) & $8.1(1.7)$ & $7.8(1.4)$ & 0.460 & $1.8(1.8)$ & $1.4(1.5)$ & 0.310 \\
ODI (\%) & $62.3(16.1)$ & $61.5(19.6)$ & 0.895 & $8.8(12.3)$ & $12(5.3)$ & 0.525 \\
Return to work status & & & & $100 \%$ & $100 \%$ & 1.000 \\
\hline
\end{tabular}

VAS: Visual Analogue Scale.

ODI: Oswestry Disability Index.

Mean value (standard deviation). $p$-values determined by Wilcoxon signed ranks test.

In obese patients, in terms of immediate postoperative complications, there were no procedurerelated complications such as infection and incidental durotomy. Two patients had late reherniations. One of them had tolerable pain, requiring conservative treatment with nerve root block, oral analgesics, physical therapy and showed good recovery. The other patient required another PELD surgery.

In control patients, there was one early reherniation which occurred within a months after PELD, which patients underwent conventional microdiscectomy.

\section{Discussion}

Recent meta-analyses and systematic reviews have reported that the transforaminal PELD is comparable or superior to the conventional open discectomy in terms of the effectiveness and minimal invasiveness for soft disc herniations. PELD can be performed though a minimal skin incision, under local anesthesia. Introduction of new techniques, scopes, and instruments overcame some of the technical limitation and increased the spectrum of indications for PELD [7].

The minimal traumatic nature of PELD decreases the perioperative complications in obese patients mainly infection and wound complications. Another benefit of PELD over microdiscectomy is that the entire procedure can be performed under local anesthesia. Thus, with respect to comorbidities in obese patients, surgeons can avoid complications associated with general anesthesia [8]

In our study population, we treated patients with dilated cardiomyopathy, poorly controlled diabetes and hypertension without the occurrence of any life threatening complications. PELD permits early mobilization and early return to work.

Decreased muscle strength and spine mobility caused functional disability, especially in older, obese patients and patients with post-operative pain, however there was no paraspinal muscle trauma during PELD. The ultimate goal of surgical treatment for disc herniation is early return to function of the patient [9].

PELD has advantages in reducing post-operative recovery time and promoting pain free status. Many other authors reported treatment of obese patients with minimally invasive surgical techniques. Their results are in agreement with ours; a less invasive approach helps minimize infections and woundrelated complications [10].

In a study conducted by Cole et al., on 32 obese patients with lumbar disc herniation treated by minimally invasive discectomy technique, the overall complication rate was $12.5 \%$ including 2 recurrent disc herniation requiring reoperation and no infectious complications. Interestingly, the most common complication was incidental durotomy, found in $9.4 \%$ of the patients. This could be related to the greater working distance necessary in obese patients. There were no cases of incidental durotomy in present study. The endoscopic view during PELD is independent of the working distance between skin and intervertebral disc [11]

The incidence of dural tear in PELD is as low as $1.1 \%$ compared to $3.1-14 \%$ in conventional spine surgery [12].

In the present study, obese group had 3 (10\%) cases of symptomatic reherniations with only 1 (3.3\%) patient required revision PELD at the same level with improved sciatica. On the other hand, control group showed 2 cases of early reherniation and 1 case of late reherniation, of which $2(5.5 \%)$ early reherniations underwent open microdiscectomy.

The incidence of reherniation of obese group in the present study seems to be relatively higher compared with normal weight group; this is due to the relatively decreased decompression caused during piecemeal removal of disc material and the 
possibility of hidden fragments being overlooked. The relative high recurrence rate in obese might not be limited to the technical difficulties of PELD. In fact, there was only 1 case (3.3\%) of a revision operation in obese group because of reherniation but control group had 2 cases $(5.5 \%)$ of revision operations.

The incidence of complications after conventional spinal surgery is generally reported to be higher in obese patients than in normal weight populations, especially in terms of wound problems and infections. Although the overall clinical outcome in obese patients after lumbar spine surgery is not inferior to that in the normal weight population [3].

The increased complication rates in obese patients can be attributed to technical difficulties associated with a deep surgical field; operations taking more time, thus increasing the chances of contamination; more paraspinal muscles trauma; and necrosis of the back muscles and subcutaneous tissue because of more forceful retraction during surgery.

Wound dehiscence is also found in obese patients, probably because of increased tension on the fascial edges at the time of wound closure and/or hematoma/seroma that creates internal tension on sutured incisions. The infectious complication rate of PELD is very low, and there were no infectious complications in the present study population [13].

Although PELD requires steep learning curve, it seems to be stable and acceptable with proper training and suitable patient selection. Observation of experienced surgeons and attending workshops for training period could be helpful for inexperienced surgeon [14]

In comparison to the control group of non obese patients who underwent PELD the results were comparable except for an increase in the number of reherniations by one patient, an increase in hospital stay for the management of comorbidities and increased operative time in some cases due to technical difficulties encountered due to obesity.

\section{Conclusion:}

PELD in obese patients has a favorable outcome compared to conventional spine surgery in terms of perioperative infection and wound complications, in addition to its favorable clinical outcomes. Obese patients with severe comorbidities, who are at risk from general anesthesia, can be treated safely with PELD. Considering the increasing prevalence of obesity PELD could be a good alternative minimally invasive technique for surgical treatment of radiculopathy caused by lumbar disc herniation.

\section{References}

1- GALAL O.M.: The nutrition transition in Egypt: Undernutrition and the food consumption context. Public Health Nutrition, 5 (1A): 141-8, 2002.

2- YUAN LI, JUN-JUN SHI, JIE REN, HAI-SHAN GUAN, et al.: Relationship between obesity and lumbar disc herniation in adolescents, Aug. 25; 33 (8), 2020.

3- GENNADIY A., SCOTT D., NICHOLAS J., SANFORD E. EMERY, et al.: Complexities of spine surgery in obese patient populations: A narrative review. The Spine Journal 20: 501-11, 2020.

4- TELFEIAN A.E., REITER G.T., DURHAM S.R. and MARCOTTE P.: Spine surgery in morbidly obese patients. J. Neurosurg., 97 (1 Suppl): 20-4, 2002.

5- MAROON J.C.: Current concepts in minimally invasive discectomy. Neurosurgery, 51 (5 Suppl): S137-145.6, 2002.

6- HEALTH N.I.O.: Clinical Guidelines on the Identification, Evaluation, and Treatment of Overweight and Obesity in Adults--The Evidence Report. National Institutes of Health. Obes. Res., 6 (Suppl 2): 51S-209S, 1998.

7- YONG AHN: Endoscopic spine discectomy: Indications and outcomes International Orthopaedics (SICOT), 43: 909-16, 2019.

8- RUETTEN S., KOMP M., MERK H. and GODOLIAS G.: Full-endoscopic interlaminar and transforaminal lumbar discectomy versus conventional microsurgical technique: A prospective, randomized, controlled study. Spine (Phila Pa 1976), 33 (9): 931-9, 2008.

9- ARJA HÄKKINEN, JARI YLINEN, HANNU KAUTIAINEN, OLAVI AIRAKSINEN, et al.: Pain, Trunk Muscle Strength, Spine Mobility and Disability Following Lumbar Disc Surgery. J. Rehabil. Med., 35: 236-40, 2003.

10- SENKER W., MEZNIK C., AVIAN A. and BERGHOLD A.: Perioperative morbidity and complications in minimal access surgery techniques in obese patients with degenerative lumbar disease. Eur. Spine J., 2011.

11- COLE J.S.T. and JACKSON T.R.: Minimally invasive lumbar discectomy in obese patients. Neurosurgery, 61 (3): 539-44; discussion 544, 2007.

12- AHN Y., LEE H.Y., LEE S.H. and LEE J.H.: Dural tears in percutaneous endoscopic lumbar discectomy. Eur. Spine J., 20 (1): 58-64, 2011.

13- CHOI K.B., LEE C.D. and LEE S.H.: Pyogenic spondylodiscitis after percutaneous endoscopic lumbar discectomy. J. Korean Neurosurg. Soc., 48 (5): 455-60, 2010.

14- JUN SEOK BAE and SANG-HO LEE: Transforaminal full-endoscopic lumbar discectomy in obese Patients. International Journal of Spine Surgery, volume 10 article 18 doi: 10.14444/3018, 2016. 


\section{إستتصال الإنزلاق الغضروفى القطنى بمنظار الثقب العصبى العهى

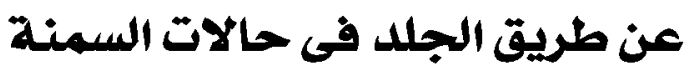

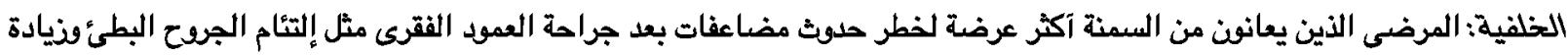

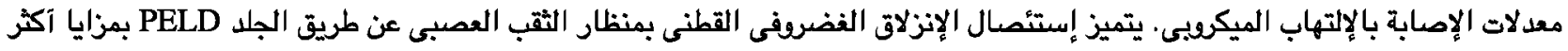

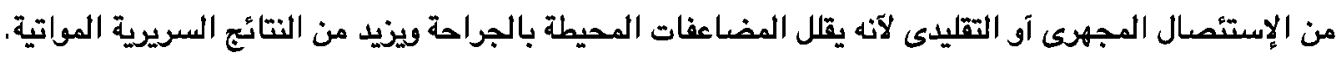

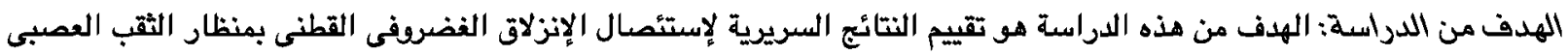

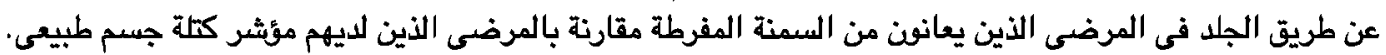

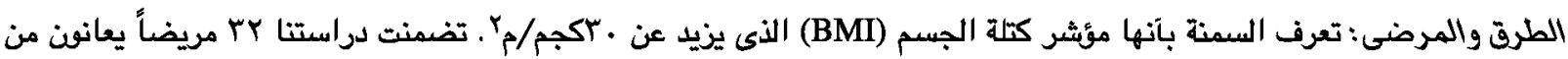

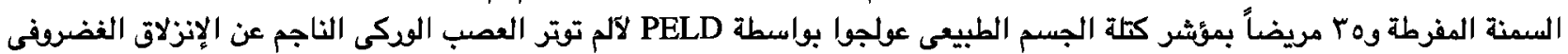

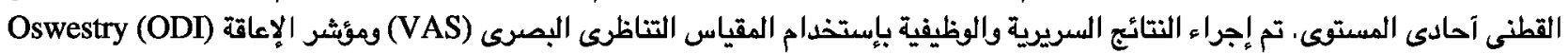

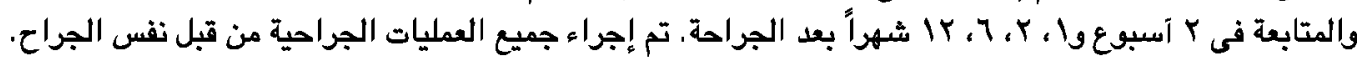

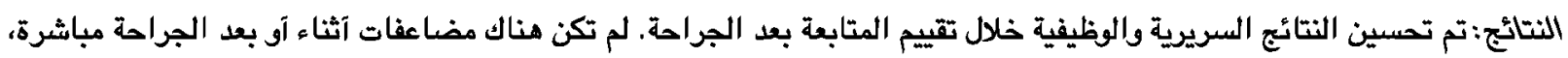

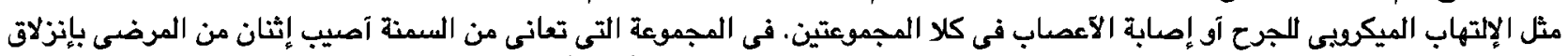

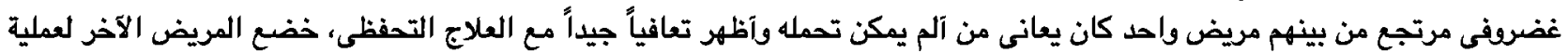
آخرى. فى المجموعة الآخرى، كانت هناك حالة إرتجاع واحدة والتى خضع المريض لإستئصالها عن طريق الإستئصال المجهرى. خاتمة: PELD هى تقنية فعالة وآمنة وذات تدخل جراحى محدوف لمرضى السمنة ، يقلل PELD من معدلات الإنس الإعتلال بعد الجراحة ويسمح

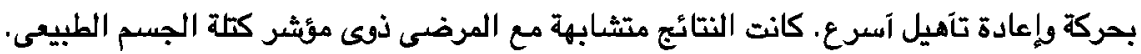

